\title{
ChemComm
}

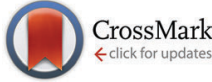

Cite this: Chem. Commun., 2014, 50, 10683

Received 28th April 2014, Accepted 21st July 2014

DOI: $10.1039 / \mathrm{c} 4 \mathrm{cc03140g}$

www.rsc.org/chemcomm

\section{LCST-type polymers based on chiral-polymeric ionic liquids $\dagger$}

\author{
Silvia Montolio, ${ }^{a}$ Laura Gonzáez, ${ }^{a}$ Belén Altava, ${ }^{a}$ Heikki Tenhu, ${ }^{\text {b }}$ \\ María Isabel Burguete, ${ }^{a}$ Eduardo García-Verdugo*a and Santiago V. Luis*a
}

The self-assembly of linear polymers containing chiral IL units generates a high-order supramacromolecular structure with a complex hierarchical architecture, which is able to exhibit thermoresponsive behavior (lower critical solution temperature: LCST) with different structural elements that can be used to fine tune this LCST.

Ionic liquids (ILs) encompass a variety of compounds and materials with great potential for applications ranging from new chemical technologies to use in industrial processes. Their physicochemical properties depend on the interactions established between the participating cations and anions that can determine variations in the self-assembled structure. Indeed, ILs have been described as "polymeric supramolecular fluids" and, consequently, as systems highly structured in the liquid state. ${ }^{1}$ Interestingly, polymers having functionalities similar to those of ILs (polymeric ionic liquids: PILs) have been pursued for developing new advanced materials, which can provide all beneficial properties of ILs without their associated drawbacks. ${ }^{2}$ Thus, the preparation of functional nanostructured materials or composites based on ILs represents an exciting and significant area of opportunity for developing multifunctional, hierarchically structured materials. ${ }^{3}$ As for ILs, one important advantage of PILs is their potential for displaying a large level of chemical and structural diversity and, hence, physico-chemical characteristics. ${ }^{4}$ Among them, chirality can be considered one of the most interesting characteristics, ${ }^{5}$ and we have reported a simple and robust modular synthetic strategy that leads to a large variety of configurationally and structurally diverse chiral ionic liquids (CILs). ${ }^{6,7}$ The in-depth study of these CILs has allowed us to analyse in detail the structure-property relationship for these compounds. ${ }^{6}$

Here, we report the synthesis and LCST-type phase transition based on a new class of chiral-polymeric ionic liquids (CPILs).

\footnotetext{
${ }^{a}$ Universidad Jaume I, Departamento de Química Inorgánica y Orgánica, Campus del Riu Sec,E-12071 Castellón, Spain.E-mail: cepeda@uji.es, luiss@uji.es

${ }^{b}$ Laboratory of Polymer Chemistry, Department of Chemistry, University of Helsinki, Finland

$\dagger$ Electronic supplementary information (ESI) available. See DOI: 10.1039/c4cc03140g
}

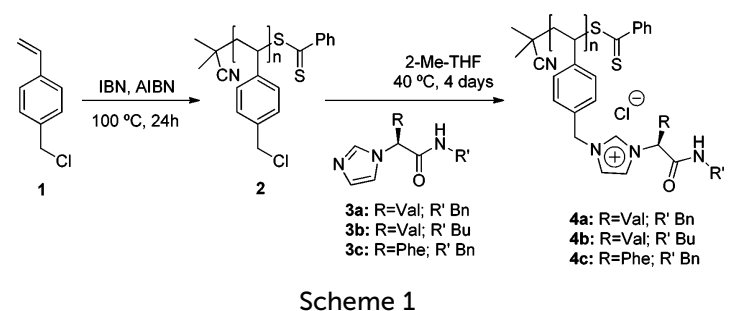

These CPILs were prepared by chemical modification of the corresponding poly(vinylbenzyl chloride) (poly(VBC)) linear polymers (2) (Scheme 1) prepared by bulk RAFT polymerization of $p$-chloromethylstyrene (1), at $100{ }^{\circ} \mathrm{C}$ for $24 \mathrm{~h}$ (100:1:0.1 $[\mathrm{M}]:[\mathrm{CTA}]:[\mathrm{I}]$ molar ratio), with IBN as a chain transfer agent and AIBN as an initiator. The poly(VBC)-2 was obtained with a $56 \%$ polymerization yield, a molecular weight of $18.9 \mathrm{~kg} \mathrm{~mol}^{-1}$ and a polydispersity of $1.5{ }^{8}$ The corresponding CPILs-4a-c were prepared by substitution of the chloride groups by different chiral imidazoles (CILs-3a-c) derived from several amino acids with variable $\mathrm{N}$-amide substitution (Scheme 1 and $\mathrm{ESI} \dagger$ ). ${ }^{6}$

To our surprise, and as observed by the naked eye, the solution of CPIL-4a in chloroform became turbid when the temperature was increased, as shown in Fig. 1. ${ }^{9}$ This phenomenon is reversible when the stimulus is reversed and the poly-CPIL-4a re-dissolved upon cooling. This phenomenon is known as a lower critical solution temperature (LCST)-type phase transition. Although LCST-type behaviour has already been observed for poly( $N$-isopropylacrylamide)-PIL copolymers and PIL homopolymers, ${ }^{10}$ such a behaviour had never been observed for CPILs. In view of this observation, a solution containing $1.0 \mathrm{mg} \mathrm{mL} \mathrm{m}^{-1}$ of CPIL-4a in $\mathrm{CHCl}_{3}$ was analysed at different temperatures by UV-Vis spectroscopy and circular dichroism (CD). The temperature was monitored using a thermocouple directly inserted into the solution. The transmittance of the solution fell exponentially with temperature in the vicinity of the LCST, which was determined to be $39.8^{\circ} \mathrm{C}$, and the turbid solution became transparent again upon cooling (Fig. 2). A small hysteresis is observed due to the fact that the rate of reversion is often slower as the polymer re-dissolves. ${ }^{11}$ 


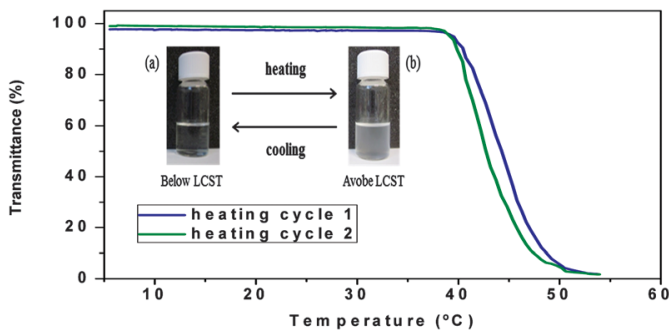

Fig. 1 Temperature behaviour of $1.0 \mathrm{mg} \mathrm{mL}^{-1}$ of $\mathrm{CPIL}-4 \mathrm{a}$ in $\mathrm{CHCl}_{3}$ (a): below LCST and (b): above LCST. The curves show the change in transmittance with temperature for this solution in the heating (blue) and cooling (green) processes.

Our previous studies, obtained for related bulk imidazolium salts, have shown that the acidic protons at the cationic component tend to form strong $\mathrm{H}$-bonds with the anion and this can extend to form a polymeric structure. Hence, for the analogous polymeric derivatives, the solvophobic effect associated with the use of the non-polar solvent $\mathrm{CHCl}_{3}$ can favor a strong interaction of the chloride anion with the amide $\mathrm{N}-\mathrm{H}$ and the imidazolium $\mathrm{C} 2$ protons in proximal imidazolium subunits, leading to the main polymeric chain to acquire a tightly twisted helix in which the ionic moieties are completely buried within the hydrophobic polymer main chain. We have previously observed such effects for another closely related family of CPILs. ${ }^{8}$ Through this arrangement, the ionic part of the polymer, displaying a strong intrapolymeric supramolecular structure, would not be exposed to the hydrophobic media. Instead, the apolar fragments would be exposed, making the polymer soluble in a non-polar solvent such as $\mathrm{CDCl}_{3}$. The CD spectra confirm this chiral structure showing a negative Cotton effect at $c a .248 \mathrm{~nm}$. It is noteworthy that the related poly(benzylbutylimidazolium-chloride) obtained by reaction of 2 with butylimidazole showed a very limited solubility in this solvent under the same conditions. This highlights the key role of the structural features of $\mathbf{4}$, in particular, the chirality and the additional amide present in the CIL subunit. The H-bonding interactions between the amide $\mathrm{NH}$ fragments and the anions are likely to fix the orientation of the structural fragments giving place to the emergence of the observed Cotton effect ascribed to the excitoncoupling of the aromatic groups arranged in a mutual chiral orientation in a well-defined environment. Preliminary computational models suggest that the presence of $\mathrm{C} 2-\mathrm{H} \cdots \mathrm{Cl}^{-} \cdots \mathrm{H}-\mathrm{NCO}$ $\mathrm{H}$-bonding between contiguous positions in the polymer favors a helical arrangement of the aromatic rings in the main chain (see ESI $\dagger$ ). Indeed, the Cotton effect declines and the $\lambda_{\max }$ shifts to

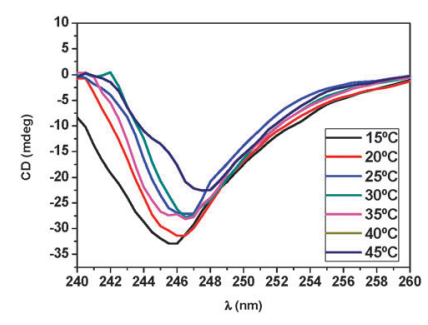

Fig. 2 Temperature-dependent CD measurement of CPIL-4a, showing a shifted and reduced CD signal at higher temperatures. higher wavelengths upon increasing temperature. This indicates a partial loss of the chiral organization with increasing temperatures leading to a larger exposure of the hydrophilic/ionic groups. Additionally, this will favor the eventual formation of interpolymeric hydrogen bonding interactions. Both factors could explain the observed precipitation of the CPIL.

VT ${ }^{1} \mathrm{H}$-NMR experiments (see Fig. S3, ESI $\dagger$ ) were carried out with CPIL-4a to determine the presence/absence of hydrogen bonding and its variation with the temperature. The chemical shifts observed for the more acidic hydrogen atoms (amide $\mathrm{NH}$ and imidazolium $\mathrm{C} 2-\mathrm{H}$ ) reveal their strong involvement in H-bonding. A small highfield shift is observed for the $\mathrm{NH}$ signal upon heating, which should be in agreement with the weakening of the H-bonding pattern involving this proton. Significant changes are observed for the proton at the stereogenic center $\left(\Delta \delta=0.13 \mathrm{ppm}\right.$ from $30{ }^{\circ} \mathrm{C}$ to $\left.75{ }^{\circ} \mathrm{C}\right)$ and additional variations are also observed for the signals corresponding to the $\mathrm{CH}$ of the isopropyl and the $\mathrm{CH}_{2}$ of the $\mathrm{N}$-benzyl substituent, suggesting that upon heating the conformational equilibria are modified and the $\mathrm{N}$-substituents and the amino acid side chain experience different average environments.

The effect of concentration on the LCST-type phase transition was also evaluated. As shown in Fig. 3, a clear dependence was observed. It decreases with increasing CPIL concentration. According to measurements from $0.5 \mathrm{mg} \mathrm{mL}^{-1}$ to $2.5 \mathrm{mg} \mathrm{mL}^{-1}$, the LCST value decreased from 48.5 to $19.4{ }^{\circ} \mathrm{C}$. Additionally, we found that the polymer was already insoluble at $\mathrm{rt}$ for concentrations $\leq 5.0 \mathrm{mg} \mathrm{mL}^{-1}$. This indicates that the competence between the formation of intrapolymeric and interpolymeric supramolecular structures is key for the observed LCST behavior.

It has been already reported that the LCST of IL-based systems strongly depends on their hydrophobicity/hydrophilicity balance. $^{12}$ The intrinsic structural tunability of the chiral imidazoles could also be used to fine tune their LCST properties. Thus, we evaluated the role of the amino acid residue and the amide substitution through the synthesis of CPILs $\mathbf{4 b}$ and $\mathbf{4 c}$. Their thermoresponsive behavior was also studied in chloroform at $0.5 \mathrm{mg} \mathrm{mL}^{-1}$ concentration.

Table 1 gathers the data obtained. The substitution of the benzyl N-substituent by an $N$-butyl fragment (CPIL 4 b) led to a shift of the LCST to higher temperature, from 48.5 to $58.8{ }^{\circ} \mathrm{C}$ (Table 1, entries 1 and 3). In contrast, when the original amino acid used for the synthesis of the imidazole ring changed from (L)-valine (CPIL 4a) to (L)-phenylalanine (CPIL 4c) the transition

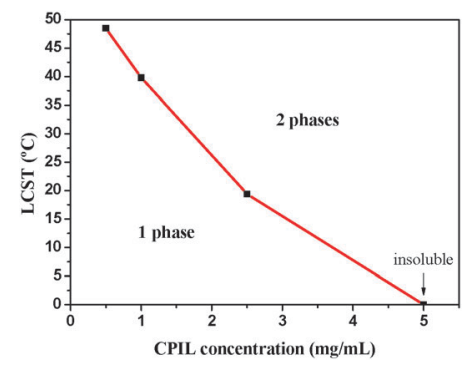

Fig. 3 Plot of the LCST vs. CPIL-4a concentration. 
Table 1 LCST values in $\mathrm{CHCl}_{3}{ }^{a}$

\begin{tabular}{llllllll}
\hline Ent. & CPIL & $\mathrm{R}$ & $\mathrm{R}^{\prime}$ & $\mathrm{X}^{-}$ & $c$ & $\mathrm{LCST}^{b}$ & $T_{\mathrm{g}}{ }^{c}$ \\
\hline 1 & CPIL-4a & (L)-Val & $\mathrm{Bn}$ & $\mathrm{Cl}^{-}$ & 0.5 & 48.5 & 156 \\
2 & CPIL-4a & (L)-Val & $\mathrm{Bn}$ & $\mathrm{Cl}^{-}$ & 1 & 39.8 & \\
3 & CPIL-4b & (L)-Val & $n$-Bu & $\mathrm{Cl}^{-}$ & 0.5 & 58.8 & 163 \\
4 & CPIL-4c & (L)-Phe & $\mathrm{Bn}$ & $\mathrm{Cl}^{-}$ & 0.5 & 12.5 & 149 \\
5 & CPIL-5 & (L)-Val & $\mathrm{Bn}$ & $\mathrm{NTf}_{2}{ }^{-}$ & 0.5 & 43.5 & 86.3 \\
6 & CPIL-5 & (L)-Val & $\mathrm{Bn}$ & $\mathrm{NTf}_{2}{ }^{-}$ & 1 & 31.9 &
\end{tabular}

${ }^{a}$ The LCST value was taken as the temperature at which the transmittance of the mixture fell below $90 \%$ during heating. $\mathrm{CHCl}_{3}$ stabilised with $2 \%$ ethanol. ${ }^{b}$ LCST in ${ }^{\circ} \mathrm{C} .{ }^{c} 10{ }^{\circ} \mathrm{C} \mathrm{min}{ }^{-1}$.

temperature considerably decreased from 48.5 to $12.5{ }^{\circ} \mathrm{C}$ (Table 1, entries 1 and 4). More likely, the observed changes can be due to the potential of aromatic groups to interfere with the formation of a suitable intrapolymeric supramolecular helical structure through their participation in aromatic interactions.

Finally, the nature of the counteranion in the CPIL was evaluated. Thus, CPIL-4a was converted into CPIL-5 with LiNTf $_{2}$ in $\mathrm{MeOH}$ at rt. The exchange of $\mathrm{Cl}^{-}$by a non-basic, non-coordinating anion such as $\mathrm{NTf}_{2}{ }^{-}$is accompanied by a slight decrease in the LCST from $48.5{ }^{\circ} \mathrm{C}$ to $43.5{ }^{\circ} \mathrm{C}$ at $0.5 \mathrm{mg} \mathrm{mL}^{-1}$ (Table 1, entries 1 and 5). The less coordinative nature of $\mathrm{NTf}_{2}^{-}$will lead to weaker ion-cation interactions in CPIL-5 than in CPIL-4a. Accordingly, the signals of the

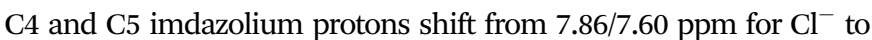
$7.77 / 7.44 \mathrm{ppm}$ for $\mathrm{NTf}_{2}{ }^{-13}$ In this way, the helical structure is less favored and the precipitation of the polymer under heating takes place earlier. When the concentration of CPIL-5 is doubled, the LCST shows the same trend observed for $\mathbf{4 a}$, decreasing from $43.5{ }^{\circ} \mathrm{C}$ to $31.9{ }^{\circ} \mathrm{C}$ (Table 1 , entries 5 and 6 ).

Additionally, we carried out differential scanning calorimetry (DSC) for the different CPILs. For bulk chiral ILs, the study of their phase transitions has provided important insights into their supramolecular structure, mainly associated with the presence of $\mathrm{H}$-bonding interactions, and establishes the appropriate structurephysical property relationship. ${ }^{6,7}$ For CPILs 4 and 5, the DSC curves for the third heating cycle (see ESI $\dagger$ and Table 1) show, in general, the presence of a glass transition temperature $\left(T_{\mathrm{g}}\right)$, as confirmed by hot-plate optical microscopy experiments, following a similar trend to LCST values. CPIL-4b presents the highest $T_{\mathrm{g}}$ $\left(163{ }^{\circ} \mathrm{C}\right)$ and LCST $\left(58.8^{\circ} \mathrm{C}\right)$ whereas CPIL-4c presents the lowest $T_{\mathrm{g}}$ $\left(149^{\circ} \mathrm{C}\right)$ and LCST $\left(12.5^{\circ} \mathrm{C}\right)$. The change in the counter anion from $\mathrm{Cl}^{-}$(more coordinating) to $\mathrm{NTf}_{2}{ }^{-}$(less coordinating) is reflected in a decrease of both melting (from $156{ }^{\circ} \mathrm{C}$ to $86{ }^{\circ} \mathrm{C}$ ) and LCST (from $48.5{ }^{\circ} \mathrm{C}$ to $43.5{ }^{\circ} \mathrm{C}$ ) temperatures. The former data suggest that the same structural parameters are responsible for both phenomena (LCST and $T_{\mathrm{g}}$ ) involving changes in the structure/conformation of the polymer chain and the breaking/reforming of intrapolymeric $\mathrm{H}$-bonds and other interactions induced by the variation of the temperature.

Potential applications of these systems are important. A thermoresponsive polycation with tunable LCST can be applied, for example, for nanoparticle stabilization and manipulation. Taking this into consideration, stabilized AuNPs were prepared by direct synthesis from $\mathrm{AuCl}_{4}{ }^{-}$in the presence of polymer 2 prepared by RAFT polymerization. ${ }^{14}$ The thiocarbonylthio moiety of polymer 2 can

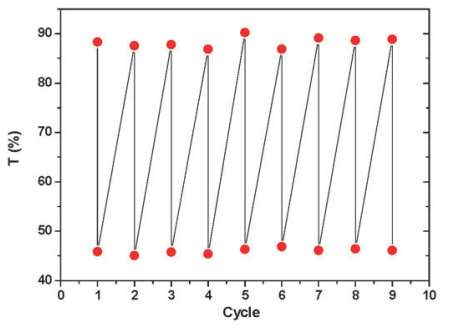

Fig. 4 Reversible LCST behaviour of AuNPs-CPIL-4a.

act as an anchoring group for the attachment to gold surfaces. The further quantitative modification of the chloromethyl groups allowed the introduction of chiral imidazolium units leading to the AuNPs-CPIL-4a nanocomposite. To our delight, this system also showed a LCST behavior $\left(31.0{ }^{\circ} \mathrm{C}, 1 \mathrm{mg} \mathrm{mL}{ }^{-1}\right.$ in $\left.\mathrm{CHCl}_{3}\right)$. The system is reversible, not showing any signal of NP aggregation after nine consecutive cycles of heating and cooling (Fig. 4).

Our results demonstrate that CPILs based on chiral imidazolium salts can be used to build up polymers with a well-organized secondary structure. The right self-assembly of the IL-like units generates a high-order supramolecular structure with a complex hierarchical architecture, which can provide polymers with a thermoresponsive behavior. The different structural vectors of the CILs, namely the nature of the substitution at the chiral stereocenters and the amide substitution, can be easily modified to fine tune their LCST performance. These vectors are able to induce structural directionality ("entropic effect") on the polymer main chain mainly through well-defined networks of supramolecular synergetic interactions. Furthermore, the presence of additional groups in the polymer allowed us to transfer these properties to 3D-hierarchical structures such as AuNPs-CPILs composites, opening a new avenue for the preparation of chiral polymeric IL- stabilized AuNPs for different applications.

Financial support from CICYT-MINECO (CTQ 2011-28903C02-01) GV (PROMETEO/2012/020) and Pla de Promoció de la Investigació de la Universitat Jaume I (P1 1B2013-37) is acknowledged. S.M (FPU AP2012-0667) thanks MINECO for personal funding. Cooperation of the SCIC of the UJI for instrumental analyses is acknowledged.

\section{Notes and references}

1 J. Dupont, Acc. Chem. Res., 2011, 44, 1223-1231.

2 P. Wasserscheid and T. Welton, Ionic Liquids in Synthesis, Wiley-VCH, Weinheim, 2007.

3 (a) D. Mecerreyes, Prog. Polym. Sci., 2011, 36, 1629; (b) J. Yuan and M. Antonietti, Polymer, 2011, 52, 1469.

4 (a) K. Nakamura, K. Fukao and T. Inoue, Macromolecules, 2012, 45, 3850; (b) V. Sans, N. Karbass, M. I. Burguete, V. Compañ, E. García-Verdugo, S. V. Luis and M. Pawlak, Chem. - Eur. J., 2011, 17, 1894; (c) P. M. Carrasco, A. Ruiz De Luzuriaga, M. Constantinou, P. Georgopanos, S. Rangou, A. Avgeropoulos, N. E. Zafeiropoulos, H.-J. Grande, G. Cabañero, D. Mecerreyes and I. Garcia, Macromolecules, 2011, 44, 4936.

5 (a) K. Bica and P. Gaertner, Eur. J. Org. Chem., 2008, 3235; (b) A. Winkel, P. V. G. Reddy and R. Wilhelm, Synthesis, 2008, 999; (c) X. Chen, X. Li, A. Hu and F. Wang, Tetrahedron: Asymmetry, 2008, 19, 1; (d) A. D. Headley and B. Ni, Aldrichimica Acta, 2007, 40, 107; (e) C. Baudequin, D. Brjgeon, J. Levillain, F. Guillen, J.-C. Plaquevent and A.-C. Gaumont, Tetrahedron: Asymmetry, 2005, 16, 3921.

6 L. González, B. Altava, M. Bolte, M. I. Burguete, E. García-Verdugo and S. V. Luis, Eur. J. Org. Chem., 2012, 4996-5009. 
7 (a) N. Ríos-Lombardía, E. Busto, V. Gotor-Fernández, V. Gotor, R. Porcar, E. García-Verdugo, S. V. Luis, I. Alfonso, S. GarcíaGranda and A. Menéndez-Velázquez, Chem. - Eur. J., 2010, 16, 836; (b) R. Porcar, N. Rios-Lombardia, E. Busto, V. Gotor-Fernandez, J. Montejo-Bernardo, S. Garcia-Granda, S. V. Luis, V. Gotor, I. Alfonso and E. Garcia-Verdugo, Chem. - Eur. J., 2013, 19, 892.

8 E. Karjalainen, D. F. Izquierdo, V. Martí-Centelles, S. V. Luis, H. Tenhu and E. García-Verdugo, Polym. Chem., 2014, 5, 1437-1446. $9 \mathrm{CHCl}_{3}$ stabilised with $2 \%$ of ethanol.

10 (a) Y. Men, H. Schlaad and J. Yuan, ACS Macro Lett., 2013, 2, 456; (b) Y. Khono, Y. Deguchi and H. Ohno, Chem. Commun., 2012,
48, 11883; (c) J. Yuan, H. Schlaad, C. Giordano and M. Antonietti, Eur. Polym. J., 2011, 47, 772.

11 Y. Kohno and H. Ohno, Aust. J. Chem., 2011, 65, 91.

12 Y. Khono, H. Arai, S. Saita and H. Ohno, Aust. J. Chem., 2011, 64, 1560.

$13 \mathrm{C} 2-\mathrm{H}$ is the most acidic proton in imidazolium fragments and should be the most affected by the anion change. However, its signal cannot be observed in $\mathrm{CD}_{3} \mathrm{OD}$ as it is acidic enough to exchange with the solvent. Nevertheless, $\mathrm{C} 4-\mathrm{H}$ and $\mathrm{C} 5-\mathrm{H}$ protons are also relatively acidic and are also affected by the coordinating ability of the anion.

14 J. Shan and H. Tenhu, Chem. Commun., 2007, 4580. 